\title{
Stock Trading, Information Production, and Executive Incentives*
}

\author{
Qiang Kang ${ }^{\dagger}$ \\ University of Miami \\ Qiao Liu $\ddagger$ \\ University of Hong Kong
}

This Draft: June 2008

\footnotetext{
${ }^{*}$ We appreciate comments from an anonymous referee which greatly improved the paper. We thank Gennaro Bernile, David Blackwell, Tim Burch, Stephen Chiu, John Core, Gerald Lumer, Craig MacKinlay, Wing Suen, James Wang, Xianming Zhou and seminar participants at the University of Hong Kong, the University of Pennsylvania, Hong Kong University of Science and Technology, and the 2006 American Finance Association annual meeting for many useful suggestions. We thank Clara Vega and Rong Qi for sharing programming code and offering computation suggestions, and Tim Burch and Kai Li for providing us with part of the data used in our empirical analysis. Financial support from the University of Hong Kong and the University of Miami (Kang) and the University Grants Committee of the Hong Kong Special Administrative Region (Projects HKU7472/06H and HKU747107H) are gratefully acknowledged. All errors remain our own responsibility.

${ }^{\dagger}$ Corresponding author. Finance Department, University of Miami, P.O. Box 248094, Coral Gables, FL 331246552. Phone: (305)284-8286. Fax: (305)284-4800. E-mail: q.kang@miami.edu.

${ }^{\ddagger}$ School of Economics and Finance, University of Hong Kong, Pokfulam, Hong Kong. Phone: (852)2859-1059. Fax: (852)2548-1152. E-mail: qliu@hku.hk.
} 


\title{
Stock Trading, Information Production, and Executive Incentives
}

\begin{abstract}
This paper investigates the effect of stock market microstructure on managerial compensation schemes. We propose and empirically demonstrate that the sensitivity of chief executive officer's (CEO's) compensations to changes in stockholders' value is higher when the stock market facilitates the production and aggregation of private or public information. Using stock trading data and analysts' earnings forecast data, we construct five different measures of the information content in stock prices. These measures, separately and jointly, account for the cross-sectional variations in CEO pay-performance sensitivity well. Our results are robust to the choice of samples, incentive measures, model specifications, and estimation methods. We extend the analysis to nonCEO executives and executive teams and find similar results.
\end{abstract}

JEL Classification: D80; G14; G34; J33

Keywords: Market microstructure; Pay-performance sensitivity; Probability of informed trading (PIN); Analysts' earnings forecasts 


\section{Introduction}

Managerial incentives are related to stock market microstructure. As well recognized in the market microstructure literature, the stock market works as an information aggregator in a stock price formation process; both public and private information are impounded into the stock price. On the other hand, the optimal contracting literature calls for the use of informative signals about managerial behavior in contract designing. Naturally, at the confluence of market microstructure and optimal contracting, we expect that informative stock prices convey to the principal useful information about the manager's effort, which the principal can exploit to better structure managerial incentives. Besides, informative stock prices also send meaningful signals to financial markets about the need for better corporate governance, which again helps incentivize managers to work in the interest of shareholders. Despite the prominent role of stock market information production in the optimal contracting, relatively little research, especially empirical research, has been done in this area except Holmstrom and Tirole (1993). We aim to fill the gap in this paper by linking executive compensation schemes to some market microstructure related variables.

Our paper makes several contributions to literatures. This study contributes to the executive compensation literature by empirically examining and identifying stock market informativeness as a new and important determinant of managerial incentives. It has become a common practice to use stock grants, option grants, and other forms of equity-related incentive pay. Researchers have documented several important determinants of equity-based incentives such as firm size, return volatility (risk), growth opportunities, CEO tenure (or CEO reputation), ownership structure, industry, and time. ${ }^{1}$ Although today the bulk of executive compensation is stock-based, the linkage of compensation schemes to stock trading and stock price informativeness is yet to be mapped out empirically. We extend Grossman and Stiglitz's (1980) reasoning to interpret the stock price informativeness in terms of the amount of information about firm fundamentals impounded into stock prices; ${ }^{2}$ we report robust evidence that enriched information content in stock prices

\footnotetext{
${ }^{1}$ See, for example, Demsetz and Lehn (1985), Smith and Watts (1992), and Schaefer (1998) for research on firm size, Garen (1994), Aggarwal and Samwick (1999), and Jin (2002) for research on return volatility (risk), Smith and Watts (1992) and Gaver and Gaver (1993) for research on growth opportunities, Bertrand and Mullainathan (2001) and Milbourn (2003) for research on CEO tenure, and Ely (1991) and Murphy (1999) for research on industry and year effects. Hartzell and Starks (2003) explore how ownership, and especially institutional investors, affects managerial incentives.

${ }^{2}$ In this paper we use stock price informativeness, stock market information production, and information content of stock prices interchangeably. They all refer to the extent to which stock prices incorporate private and public
} 
better reconnects executive pay to firm performance, suggesting that a stock market microstructure facilitating the production and aggregation of information helps discipline executive pay practices.

Second, our study also adds one new perspective to the growing literature that examines how stock markets, especially the ways stock markets aggregate public and private information, affect the efficiency of various corporate decisions at the managerial level (e.g., Subrahmanyam and Titman, 1999; Durnev et al., 2004; and Chen et al., 2006). In a similar vein of spirits, we argue and present evidence that stock market microstructure determines the amount of information content in stock prices, which in turn affects the compensation contracting decisions of the principals. On this issue, Holmstrom and Tirole (1993) are among the first researchers who show analytically that stock prices incorporate performance information that cannot be readily extracted from the firm's accounting data, and thus that the principal can use the inferred information to design a more effective compensation contract, but they stop short of offering empirical evidence.

Third, because the executive compensation scheme is one important (passive) corporate governance mechanism, to our best knowledge, ours is among the first few papers to explore the relation between corporate governance and market microstructure characteristics [see also Subrahmanyam (2007)].

We focus on empirically testing the prediction that there is a positive relation between payperformance sensitivity and the amount of information in stock prices via informed trading. Following the compensation literature (e.g., Jensen and Murphy, 1990; Hall and Liebman, 1998; Aggarwal and Samwick, 1999; and Murphy, 1999), we measure the managerial incentive by payperformance sensitivity, which characterizes the empirical relation between changes in executive firm-related wealth and changes in shareholder wealth, and we rely mainly on the stock-based payperformance sensitivity to interpret the empirical results. We construct five different measures for the stock price informativeness. We use stock trading data to compute the probability of informed trading $(P I N)$ for each firm-year observation. ${ }^{3}$ We also utilize analyst earnings forecast data to

${ }^{3}$ Easley et al. (2002) find that stocks with high PINs on average earn high returns and argue that $P I N$ is a measure of information risk. They interpret that $P I N$ captures incremental private information impounded into stock prices and that "(PIN) measures the prevalence of private information in a microstructure setting... It has been shown to have predictive power as a measure of private information (pp. 2194)". By formally developing a rationalexpectation equilibrium model, Easley and O'Hara (2004) further rationalize that investors demand higher returns to hold stocks with greater private information because informed investors are better able to shift their portfolio to incorporate new information and uninformed investors are thus disadvantaged. In this sense, PIN as a measure of information risk and $P I N$ as a proxy for information content of stock prices are the two sides of a coin.
} 
construct four other proxies for stock price informativeness because there is strong evidence to link analyst forecasts to properties of information environment both analytically and empirically (see, e.g., Ajinkya and Gift, 1985; Holthausen and Verrecchia, 1990; Barry and Jennings, 1992; Abarbanell et al., 1995; Wiedman, 1996; and Barron et al., 1998). The five variables arguably capture different aspects of stock price informativeness. In particular, the PIN variable likely estimates the amount of private information held by a trader on a specific stock — in a given time interval and all else being equal, stocks with high $P I N$ have more private information impounded into stock prices; the other four informativeness proxies associated with financial analyst activity likely capture the amount of public information impounded into stock prices.

We conduct various empirical tests of the hypothesis that pay-performance sensitivity increases with respect to stock price informativeness, and we find strong empirical support for this hypothesis. Specifically, after controlling for institutional ownership and concentration as well as other factors identified in prior studies, pay-performance sensitivity is strongly and positively related to PIN, but significantly and negatively related to the four informativeness proxies associated with financial analyst activity. The results are economically significant, too. Depending on the use of informativeness proxies in the regressions, per $\$ 1,000$ increase in shareholder value, the CEO pay-performance sensitivities at the 25th percentile of stock price informativeness are $\$ 1.78$ to $\$ 5.4$ smaller than the CEO pay-performance sensitivities at the 75 th percentile of price informativeness, representing $13.89 \%$ to $42.04 \%$ reductions from the median pay-performance sensitivity in our sample. The findings are robust to the choice of estimators, samples, time periods, incentive measures, model specifications, and estimation methods. We further extend our analysis to nonCEO executives and "executive teams." Like CEO pay-performance sensitivities, executive pay-performance sensitivities, individually or in teams, are positively related to stock price informativeness. We also find that the impact of stock price informativeness on pay-performance sensitivity is much larger for CEOs than for nonCEO executives. Our empirical findings suggest that an informationally efficient stock market induces firms to rely more heavily on equity-based incentive contracts. The results also suggest that, different from the assumption made by Holmstrom and Tirole (1993), ownership structure is not the sole, and indeed, not the main channel through which a firm's stock liquidity and/or stock price informativeness affects managerial incentives.

The paper proceeds as follows. Section 2 develops the main hypothesis of the paper. Section 3 
presents the data and our empirical method. Section 4 reports the empirical results and conducts the robustness analysis. Section 5 extends our empirical analysis to nonCEO executives and executive teams. Section 6 concludes.

\section{Development of Hypothesis}

Managerial incentives are related to stock market microstructure. Informative stock prices convey to the principal useful information about the manager's effort, which the principal can exploit to better structure managerial incentives. Informative stock prices may also send meaningful signals to financial markets about the need for better corporate governance. The effectiveness of various corporate governance mechanisms, e.g., institutional investors pressure and the market for corporate control, depends on the stock markets. Hartzell and Starks (2003) provide evidence on the impact of corporate governance on executive incentives in that institutional investors' monitoring induces managerial incentives, but they do not examine the role of stock market information production. Although stock market information production plays an important role in the practice of managerial incentive pay, the literature has yet to examine this issue rigorously.

Holmstrom and Tirole (1993) (HT hereafer) are among the first researchers to combine the process of stock price formation with the design of optimal compensation contracts. HT show that a firm's stock price incorporates performance information that cannot be extracted from the firm's current or future profit data. The amount of information contained in the stock price is useful for structuring managerial incentives. An illiquid market makes the stock price less informative and thus reduces the benefits of stock market monitoring.

In HT's model, the stock market acts as an external monitoring mechanism to align the interests of managers with those of shareholders. In the stock market, an informed party (a speculator) can take advantage of the presence of liquidity traders to disguise, and thereby profit from, his private information. Thus, the speculator has an incentive to spend resources collecting signals about the firm's fundamental value. The information is incorporated into the stock price through trading. As a result, the increased information flow into the market improves the information content of the stock price, which enables firms to design more efficient managerial contracts. HT show analytically that the pay-performance sensitivity of managerial compensation is higher when the signal observed 
by the speculator is more precise or the amount of liquidity trading is larger (i.e., see Proposition 3 in HT). Thus, the information content of a stock's price is positively related to pay-performance sensitivity.

HT highlight the importance of market microstructure in inducing executive incentives. But it is not easy to build an empirical analysis based on HT. In HT's model, ownership concentration directly determines market liquidity, which subsequently sets the level of stock price informativeness and pay-performance sensitivity. Hartzell and Starks (2003) point out that the ownership structure could also exert its impact on the pay-performance relation through a corporate governance channel. Also, in the HT's model, stock price volatility conveys the precision of the informed trader's information. A more volatile stock price implies a more liquid and informative market, resulting in better stock market monitoring. This aspect has been extensively studied in the empirical research on executive compensation, but in a different context (i.e., the study of risk-incentive relation) with mixed evidence (Garen, 1994; Aggarwal and Samwick, 1999; Core and Guay, 2002; and Jin, 2002).

To better motivate our empirical analysis, we propose another model that links informationbased stock trading to an optimal contracting process. Because the derivation of our model is completely standard and the model is not meant to be a detailed description of the realities of managerial compensation setting but to deliver the central empirical predictions, we present the model in the Appendix. In contrast to HT's model, which assumes that stock market liquidity is endogenously determined by the ownership structure, we assume that market liquidity is exogenously given. By abstracting from the ownership structure, we derive the result that information-based trading becomes more prevalent when the cost of information collection falls (or the benefit of informed trading increases), which increases the informativeness of the stock price, all else being equal. Consequently, the stock market monitoring becomes more effective to improve managerial incentives. ${ }^{4}$ We hypothesize that cross-sectional differences in stock market information production help explain cross-sectional variations in managerial incentives. The more informative the stock price, the more effective the compensation scheme in inducing managers' incentives. We test the following hypothesis for our empirical analysis:

\footnotetext{
${ }^{4}$ The key results of our model, drawn immediately from Propositions 1-2 in the Appendix, are summarized as follows: (1) Pay-performance sensitivity decreases with the manager's effort parameter and the degree of risk aversion, and increases with the degree of stock price informativeness. (2) Stock price informativeness increases with the number of informed traders, which is determined by various market microstructure parameters, e.g., the cost of collecting information, market liquidity, uncertainty of the stock value, etc.
} 
H1: Pay-performance sensitivity increases with the amount of information in stock prices.

\section{Data and Empirical Method}

Our primary data set for executive compensation is the ExecuComp database, from 1992 through 2001. The database reports annual compensation flows as well as information related to changes in the value of stock and stock option holdings for the five top-paid executives, including the CEO, for each firm appearing in the S\&P500 Index, S\&P MidCap 400 Index, and the S\&P SmallCap 600 Index. We obtain stock return data from the Center for Research in Security Prices (CRSP) Monthly Stock File and accounting information from the Compustat Annual File. We construct the five proxies for stock price informativeness from two databases. We compute a firm's probability of informed trading $(P I N)$ in a given year by using intraday trading data extracted from the Trade and Quote (TAQ) database, and calculate the four other variables by using analyst earnings forecast information retrieved from the Institutional Brokers Estimates System (I/B/E/S) History Summary File. We obtain institutional equity holdings from the Institutional Holdings database maintained by Thomson Financial. We quote all monetary terms in 1992 constant dollars, and we adjust nominal stock returns by the Consumer Price Index (CPI) to obtain real returns.

\subsection{Measuring CEO Incentives}

Among a firm's senior executives, the CEO makes most major corporate decisions and exerts the greatest influence on the firm. Accordingly, we focus on incentive provisions for CEOs. ${ }^{5}$ We measure incentives by pay-performance sensitivity, which is defined as the dollar value change in the CEO's firm-specific wealth per $\$ 1,000$ change in shareholder value (Jensen and Murphy, 1990). Recent research mainly uses the pay-performance sensitivity based on stocks and stock options, and such stock-based pay-performance sensitivity can be interpreted as the CEO's stock ownership plus incentives from stock option holdings. Using the option delta $\delta,{ }^{6}$ we calculate the stock-based

\footnotetext{
${ }^{5}$ We extend our empirical analysis to nonCEO executives and executive teams in Section 5 . We identify CEOs by the fields "BECAMECE", "LEFTOFC", and "CEOANN." Using only "CEOANN" is problematic, since there are many missing observations for the earlier periods of the sample (Milbourn, 2003).

${ }^{6}$ The symbol $\delta$ here refers to how the value of a stock option varies given a one-dollar change in the value of the underlying stock. We adopt Core and Guay's (1999) method to compute it for each option.
} 
pay-performance sensitivity as

$$
P P S_{i t}=\left(S H R O W N P C_{i t-1}+\frac{(\text { Number of Options Held })_{i t-1}}{(\text { Number of Shares Outstanding })_{i t-1}} \delta\right) \times 1000,
$$

where $S H R O W N P C$ measures the CEO's stock ownership.

Panel A of Table 1 presents the summary statistics of the CEO incentive measures. The mean and median values of the stock-based incentive measure (PPS) are $\$ 40.79$ and $\$ 12.85$, respectively, per $\$ 1,000$ change in shareholder value. The $P P S$ measure has a standard deviation of $\$ 74.59$ with a maximum value of $\$ 994.45 .{ }^{7}$ Panel A of Table 1 also reports summary statistics of the pay-performance sensitivity for all executives $P P S \_E X E$ and executive teams PPS_TEAM. We compute PPS_EXE based on equation (1) for each of the five top-paid executives within a firm (including the CEO), where $P P S \_E X E$ measures the stock-based incentive of an individual executive. We obtain PPS_TEAM by summing up PPS_EXE across all the five top-paid executives within a firm; PPS_TEAM captures the executive team's incentives. The mean and median values of PPS_EXE are $\$ 15.76$ and $\$ 2.75$, respectively, both of which are significantly smaller than those of CEO incentives. The mean (median) of PPS_TEAM is $\$ 64.41$ (\$24.25), with the majority of team incentives attributable to the CEO incentives.

\subsection{Measuring Stock Price Informativeness}

We use two sets of variables to measure the stock price informativeness in our empirical analysis. One set is the probability informed trading $(P I N)$ developed in Easley et al., $(1996,1997)$. The other set of variables are constructed based on analyst earning forecast data.

The PIN measure is constructed on the basis of Easley and O'Hara's (1992) structural market microstructure model. We justify the use of $P I N$ as an appropriate measure of stock price informativeness on two grounds: one conceptual and the other empirical. On the conceptual level, PIN directly captures the probability of informed trading in the stock market. By its very construction, informed traders act on their information if they think the information is not publicly

\footnotetext{
${ }^{7}$ As a comparison, the unreported total pay-performance sensitivity, which is defined as the dollar-value change in the CEO's total firm-related wealth per $\$ 1,000$ change in shareholder value, has a mean of $\$ 46.51$, which is higher than that of PPS, but it also has a slightly larger standard deviation (\$81.92). Its median is $\$ 13.09$, which is almost the same as the median of PPS. The stock-based incentive does not deviate much from the total incentive, corroborating the findings in prior studies that changes in the value of stock and stock option holdings account for the majority of pay-performance sensitivities (Hall and Liebman, 1998; and Murphy, 1999).
} 
known and they can benefit from the trading. A higher PIN implies a greater amount of private information reflected in a stock price. Because the information for stocks with high PINs comes more from private sources than from public sources, all else equal, these stocks may provide more incremental information to the principals to better structure managerial incentives. This intuition is consistent with the finding of Easley et al. (2002) that stocks with high PINs earn higher returns than stocks with low PINs. They argue that PIN is measure of information risk and that PIN captures private information impounded into stock prices. The information is so valuable that the uninformed traders would ask for a premium to trade against informed traders. Easley and O'Hara (2004) further develop a rational-expectation equilibrium model formally and rationalize that investors demand higher returns to hold stocks with greater private information. A growing empirical literature links the PIN measure to the informativeness of the stock market (Easley et al., 1998; Chen et al., 2006; and Vega, 2006).

Since the PIN measure has been well accepted in the finance literature, we do not present the construction procedures in this paper to save space. We follow the method used in Easley et al. (2002) and construct PIN for the period from 1993 to 2001. There are 8,456 firm-year observations after we merge the TAQ database with the ExecuComp database. Panel A of Table 2 presents summary statistics for PIN. In our sample, the average $P I N$ is 0.163 with a standard deviation of 0.051 . The median value of $P I N$ is 0.157 . The maximum $P I N$ is 0.797 with a minimum of zero. The average sample property of our PIN estimates is consistent with the sample property identified in previous studies (see, e.g, Easley et al., 2002).

Information-based trading can only be inferred by econometricians. The analyst earnings forecast literature has reported evidence to link analyst forecast error (or accuracy) and forecast dispersion with the properties of information environment. Barron et al. (1998) analytically show that the quality of common and private information can be measured using forecast dispersion (as a proxy for analyst uncertainty) and forecast error (as a proxy for analyst consensus). We thus supplement the PIN measure with four other variables using analyst earnings forecast data from the I/B/E/S History Summary File. For each firm in the ExecuComp database, we use the summary information on analyst fiscal year 1 earnings estimates in the ninth month of a fiscal year. ${ }^{8}$

\footnotetext{
${ }^{8}$ We also conduct the analysis by using summary information on the other months' fiscal year 1 earnings estimates
} 
When a firm's information production process is intense and effective, analysts following the firm's stock are more likely to agree with one another on the firm's earnings prospect (see, e.g., Holthausen and Verrecchia, 1990). We use two measures of analyst earnings forecast error. We compute $F E$ as the absolute value of the difference between mean earnings forecast and actual earnings, divided by the absolute value of actual earnings. When the actual earnings are close to zero, $F E$ can be extremely large. To deal with this problem, we calculate an alternative measure of analyst earnings forecast error, $F E P$, as the absolute value of the difference between the mean earnings forecast and actual earnings, scaled by the fiscal year-end stock price. Both FE and FEP measure the intensity of a firm's information production, and they serve as proxies for the stock price informativeness.

Panel A of Table 2 presents summary statistics for FE. It has a mean (median) of 0.444 (0.066) and a standard deviation of 5.014. The mean and median values of FEP are 0.013 and 0.002, respectively, and its standard deviation is 0.093 . Both $F E$ and $F E P$ have fat tails and are highly skewed to the right, but FEP is less skewed than FE.

Akinkya and Gift (1985), Diether et al. (2002), and Johnson (2004), among others, show that the dispersion of analyst earnings forecasts is a proxy for the information environment in which various investors trade. We define DISPER as the standard deviation of earnings forecasts scaled by the absolute value of the mean earnings forecast. If the mean earnings forecast is zero, we exclude the stock from the sample. Panel A of Table 2 presents summary statistics of DISPER for the period 1992-2001. Its mean (median) is 0.121 (0.032) and its standard deviation is 0.668.

Similar to $F E$, when the mean earnings forecast is close to zero, DISPER can be extremely large. We thus define another measure of the dispersion of analyst earnings forecasts, DISPERP, as the standard deviation of earnings forecasts scaled by the fiscal year-end stock price (and times 100). Its mean and median are 0.412 and 0.135 respectively. It has a standard deviation of 2.098. Both DISPER and DISPERP have fat tails and are highly skewed to the right, but DISPERP is less skewed than DISPER.

Panel B of Table 2 presents the bivariate Pearson correlation coefficients and their significance levels for the five price informativeness variables. After merging the five variables, the number of within that fiscal year. The summary information is stable across months and is very close to the annual average value. Results are qualitatively similar and are not reported for brevity. 
observations drops to 4,503 . In this sample, the correlation between $P I N$ and $F E$ is 0.019 and is not significant. The correlations between PIN and FEP, DISPER, and DISPERP are 0.068, 0.040, and 0.041, respectively, and all are significant at the $1 \%$ level. The correlation between $F E$ and FEP is 0.090 and significant at the $1 \%$ level, but $F E$ is not significantly correlated with either DISPER or DISPERP. The correlation between FEP and DISPER (DISPERP) is $0.110(0.562)$, and both correlations are significant at the $1 \%$ level. Finally, the correlation between DISPER and DISPERP is 0.129 and significant at the $1 \%$ level. The piecewise correlations among the five price informativeness proxies show similar patterns and are not reported for brevity. The low correlations among the five proxies (except for the correlation between $F E P$ and $D I S P E R P)$ suggest that they likely reflect different aspects of a firm's stock price informativeness. ${ }^{9}$

\subsection{Control Variables}

Panel B of Table 1 summarizes the control variables. We obtain stock return data from CRSP. We calculate the market value $(M K T V A L)$ at each fiscal year-end. Our sample comprises a range of firms with an average market capitalization of $\$ 4.29$ billion and a median of $\$ 0.86$ billion. We use the $\log$ value of market capitalization $(S I Z E)$ as one measure of firm size. The mean (median) value of $S I Z E$ is 6.91 (6.76) with a standard deviation of 1.6. The firm's annualized percentage stock return (ANNRET) averages $22.45 \%$ with a median of $11.54 \%$. The annualized percentage volatility of stock returns ( $A N N V O L)$, which we compute by using the past five years of monthly stock returns, has a mean value of $39.44 \%$ and a median value of $35.23 \%$. We extract firm-specific accounting data from Compustat. To measure a firm's growth opportunities, we calculate Tobin's $\mathrm{Q}(T O B I N Q)$ as the ratio of the market value of assets to the book value of assets. Table 1 shows that the average Tobin's Q of the firms in our sample is 2.16. Its standard deviation and median are 2.75 and 1.48, respectively. We also calculate the return on assets (ROA) as the ratio of the net income before extraordinary items and discontinued operation divided by total assets. The mean and median of $R O A$ are $3.07 \%$ and $4.13 \%$, respectively.

We construct two institutional ownership variables to control for the monitoring effect suggested

\footnotetext{
${ }^{9}$ Easley et al., 2002 and Chen et al., 2006 both argue that PIN is more likely to capture the amount of private information contained in stock prices. Piotroski and Roulstone (2004) report evidence that (financial) analyst activity increases the amount of industry and market-level information in stock prices. Thus, the four proxies based on the analyst forecast data likely reflect the amount of public information impounded into stock prices.
} 
in Hartzell and Starks (2003), and to test the assumption in the HT model that price informativeness relates to pay-performance sensitivity through ownership structure. We define INSTHOLD as the total institutional share holdings in percentage of the total number of shares outstanding. Based on HT's model, INSTHOLD should be negatively related to market liquidity and payperformance sensitivity. We also expect institutional investors to have greater influence if the shares are concentrated in the hands of larger investors. We use the concentration of institutional ownership as a proxy for institutional influence. We define INSTCON as the proportion of institutional investor ownership accounted for by the top ten institutional investors in the firm. As shown in Panel B of Table 1, on average, $56.47 \%$ of a firm's shares are owned by institutional investors, and $60.07 \%$ of the shares held by institutional investors are controlled by the top ten institutional investors.

Other control variables are CEO tenure, CEO age, industry dummies, and year dummies. We calculate CEO tenure as the number of years the executive has been the CEO of the firm as of the compensation year in ExecuComp. The mean and median of CEO tenure are 7.672 and 5.499 years, respectively. The average age for the CEOs in our sample is 55 years. Finally, we construct 20 industry dummies based on the CRSP two-digit SIC code.

\subsection{Econometric Specification and Testable Hypotheses}

Throughout our empirical analysis, we directly regress the incentive measure against a set of explanatory variables. ${ }^{10}$ This approach renders the regression results immediately interpretable. It also provides flexibility in controlling for factors that may affect pay-performance sensitivity, and has been used by many researchers such as Core and Guay (1999), Jin (2002), and Milbourn (2003). We specify the model as follows:

$$
P P S_{i, t}=\gamma_{0}+\gamma_{1} I N F O V_{i, t-1}+C O N T R O L S_{i, t-1}+\varepsilon_{i, t}
$$

In equation (2), PPS refers to the computed pay-performance sensitivity as specified in equation (1), INFOV stands for the set of price informativeness variables, i.e., PIN, FE, FEP, DISPER, and DISPERP, and CONTROLS represents a set of empirically relevant

\footnotetext{
${ }^{10}$ In earlier versions of the paper, we also try various other econometric specifications and obtain largely similar results.
} 
control variables, such as firm size, return volatility, growth opportunities, CEO tenure, level and concentration of institutional ownership, industry effects, and year effects. In several model specifications, we also control for CEO age and firm-level return on assets. Our primary coefficient of interest in equation (2) is the coefficient on stock price informativeness, $\gamma_{1}$, which captures the influence of price informativeness on incentives. We test our hypothesis by examining the sign and significance of the estimated $\gamma_{1}$.

As noted earlier, the five INFOV variables, PIN, FE, FEP, DISPER, and DISPERP, capture price informativeness from different perspectives. A larger value of $P I N$ corresponds to a more informative market, and a larger value of FE, FEP, DISPER, or DISPERP corresponds to a less informative market. Testing of our core hypothesis comprises several hypothesis tests, depending on which $I N F O V$ variable and which econometric specification is used. Specifically, using the econometric specification in equation (2), we have

H0: $\gamma_{1}=0$, versus

H1': $\gamma_{1}>0$ if the INFOV variable is $P I N$; or versus

H1": $\gamma_{1}<0$ if the INFOV variable is FE, FEP, DISPER, or DISPERP.

Given the apparent right skewness in the CEO compensation and incentive data as shown in Table 1, we follow the literature and estimate median regressions (see, e.g., Aggarwal and Samwick, 1999; Jin, 2002; and Milbourn, 2003). A median regression minimizes the sum of absolute deviations rather than the sum of squared deviations as in an ordinary least square (OLS) regression. The influence of outliers on the empirically estimated results is greatly reduced. Additionally, because the median is more robust to the presence of extreme outliers than the mean as a measure of the central tendency of a distribution, the precision of the estimates will also increase. In all median regressions we use bootstrapping methods to calculate standard errors of the estimates.

We replace each raw measure of the five price informativeness proxies with its cumulative distribution function (CDF) in both model specifications. As Aggarwal and Samwick (1999) argue, the use of CDF helps make the highly nonhomogeneous data homogeneous and the regression results economically sensible. It is also easier to transform the estimated coefficient values into pay-performance sensitivities at any percentile of the distribution of the proxies. Thus, the CDFs give the regression results more immediate economic intuition than the raw measures. 


\section{Empirical Results}

\subsection{The Baseline Results}

Our main empirical results are based on the econometric specification as in equation (2). Table 3 presents the median regression results of the stock-based pay-performance sensitivity $P P S$, defined in equation (1), by using the raw measures of the five stock price informativeness proxies. In all regressions we control for firm size, return volatility, growth opportunity, CEO tenure, total institutional holdings, concentration of institutional holdings, industry dummy, and year dummy. In Column (7) we also control for the CEO age and the return on assets.

Column (1) shows how the CEO incentives respond to the probability of informed trading $(P I N)$. The estimated coefficient of the PIN measure $\left(\gamma_{1}\right)$ is 25.284 and is statistically significant at the $1 \%$ level. All else equal, a one-standard-deviation increase in PIN yields a $\$ 1.290$ increase in PPS. The difference in PPS between any two PIN levels is calculated as the difference in the two $P I N$ values multiplied by $\gamma_{1}$. For example, because the maximum, median, and minimum $P I N$ are $0.797,0.157$, and zero, respectively, the pay-performance sensitivity at the maximum $P I N$ is $\$ 16.18$ higher than that at the median $P I N$ as a result of a $\$ 1,000$ increase in shareholder value, all else equal. The incentive with the median PIN is $\$ 3.97$ larger than the incentive with the minimum PIN. Given that the mean (median) stock-based pay-performance sensitivity in our sample is $\$ 40.787$ (\$12.845), the economic magnitude of $P I N$ on pay-performance sensitivity is significant.

Columns (2)-(5) report the median regression results of using FE, FEP, DISPER, and $D I S E R P$ as proxies for stock price informativeness. The estimates of $\gamma_{1}$ are $-0.08(F E), 39.546$ (FEP), -0.397 (DISPER), and -2.486 (DISPERP). Except for FE, the parameter of interest is statistically significant for these price informativeness proxies.

In Columns (6) and (7), we report the estimation results of using all the five informativeness measures jointly. Using the informativeness variables collectively does not improve model goodnessof-fit significantly. The pseudo R-squares in these two columns do not change much. The signs of each individual coefficient on the informativeness proxies are largely consistent with those in Columns (1)-(5), where they enter regressions individually (except for $F E$ ). The results suggest that both public and private information content in the stock price are helpful to managerial 
incentive enhancement, and lend support to the claim in Bushman et al. (2005). That is, because informed traders and financial analysts may not directly compete for the same information set, a substitute relation between private-information-based trading activities and public-informationprone analyst activities does not necessarily arise.

Table 3 also shows that the estimated coefficients of all the control variables are statistically significant and consistent in both sign and magnitude across all seven regressions. The signs and significance levels of the control variables are consistent with those in the literature and are also robust to the inclusion of return on assets and the CEO age (Column 7). For brevity, we do not discuss the detailed results.

Notably, the coefficient on the lagged total institutional share holdings INSTHOLD is significantly negative and ranges between -0.189 and -0.088 . The coefficient on the concentration of institutional share holdings INSTCON is significantly positive and spans from 0.035 to 0.154 . This result is consistent with the finding in Hartzell and Starks (2003) that institutional influence enhances managerial incentives. $^{11}$

All five measures for stock price informativeness are fat-tailed and right-skewed. A cumulativedensity-function (CDF) transformation of the raw measures helps smooth the data and yields more economically meaningful results. The PPS difference between any two percentiles of an informativeness proxy is calculated as the difference in the two percentile values multiplied by $\gamma_{1}$. Table 4, which shares the same structure as Table 3, reports the results when we use the CDFs of the raw measures as proxies for price informativeness. As shown in Columns (1)-(5), the coefficients of interest, $\gamma_{1}$, are $3.883,-3.568,-7.067,-4.961$, and -10.799 when their information variables are the CDFs of PIN, FE, FEP, DISPER, and DISPERP, respectively. All five estimates of $\gamma_{1}$ are statistically significant at the $1 \%$ level and have the expected signs, leading to a clear rejection of the null hypothesis in favor of the alternative hypothesis that stock price informativeness improves managerial incentives.

In Columns (6) and (7), we report the estimation results of using all the five informativeness

\footnotetext{
${ }^{11}$ We note that the two institutional variables only serve as control variables in our analysis. The inclusion of the two institutional variables in our regression models does not change the signs and significance levels of coefficients on the five stock price informativeness measures. This result suggests that the relation between pay-performance sensitivity and price informativeness is unlikely to be driven by the "ownership - market liquidity" channel as proposed by HT. Institutions do serve a monitoring role in enhancing managerial incentives, and this role of institutions is different from the role of stock price informativeness.
} 
measures. The findings are consistent with those in Table 3, regardless of whether return on assets and the $\mathrm{CEO}$ age are included as controls or not. Again, we find 1. the relations between PPS and various control variables are robust to the inclusion of all informativeness measures; and 2. the coefficients on $C D F(P I N), C D F(D I S P E R)$, and $C D F(D I S P E R P)$ are always significant, while the significance levels of $C D F(F E)$ and $C D F(F E P)$ decrease. Table 4 also shows that the estimated coefficients on control variables, including return on assets and the CEO age, are all statistically significant and have magnitudes similar to those in Table 3.

The estimation results have economically significant implications. When we use the CDFs of $P I N, F E, F E P, D I S P E R$, and DISPERP as proxies for price informativeness as in Columns (1)-(5), the pay-performance sensitivities estimated at the median stock price informativeness are $\$ 1.942, \$ 1.784, \$ 3.534, \$ 2.481$, and $\$ 5.4$ smaller (larger) than the pay-performance sensitivities estimated at the maximum (minimum) price informativeness, representing respective reductions (increases) of $15.12 \%, 13.89 \%, 27.51 \%, 19.31 \%$, and $42.04 \%$ relative to the median pay-performance sensitivity in our sample. If we compare the pay-performance sensitivities at the first quartile of price informativeness with the pay-performance sensitivities at the third quartile of price informativeness, we obtain the same results.

\subsection{Subperiod Analysis}

We also perform a subperiod analysis by splitting our sample into two, the bubble period from 1992 to 1999 and the post-bubble period from 2000 to $2001 .{ }^{12}$ Using the stock-based PPS as the dependent variable and the CDF transformations of the five stock price informativeness measures as the key explanatory variables, we apply median regressions to each of the two subperiods. Columns (1)-(5) and Columns (1)'-(5)' in Table 5 report the results for the 1992-1999 subperiod and the 2000-2001 subperiod, respectively. The corresponding coefficient estimates on each control variable, except the estimates on the concentration of institutional share holdings (INSTCON), have the

\footnotetext{
${ }^{12}$ We do this for three reasons: 1 . The U.S. stock market bubble burst in 2000, rendering many executives' options virtually worthless. The way in which we compute the changes in value of stock option portfolios might create a bias for firms with more out-of-money options and for firms with options that are at- or near-the-money. Comparing the results before and after the bubble burst is thus both useful and interesting. 2. We might rationally expect that a firm's incentive provision policies changed after the bubble burst, which might directly affect our results. 3. Most of the prior research uses data up to 1999. By conducting a subperiod analysis, we are able to compare our analysis with the prior research. We can also check the stability of the relation between incentives and the variables of interest.
} 
same signs and similar magnitudes and significance levels across the two subperiods. ${ }^{13}$

The estimates of the parameter of interest, $\gamma_{1}$, from the two subperiods are consistent with each other for a given stock price informativeness proxy. All of the estimates are statistically significant at the $1 \%$ level in both subperiods, except for the estimate that is significant at the $5 \%$ level when $C D F(F E)$ is used as the informativeness proxy in the post-bubble period. The magnitudes of these estimates tend to become larger in 2000-2001 than in 1992-1999, indicating that the price-informativeness-based incentive enhancement effect strengthens after the bubble burst. For example, when $C D F(P I N)$ is the informativeness measure, the estimates of $\gamma_{1}$ increase from 2.442 in the bubble subperiod to 9.443 in the post-bubble subperiod. When $C D F(D I S P E R)$ is the informativeness measure, the estimates of $\gamma_{1}$ decrease from -2.732 in the bubble subperiod to -4.544 in the post-bubble subperiod. If $C D F(D I S P E R P)$ is the informativeness measure, the estimates of $\gamma_{1}$ reduces from -7.549 in the bubble subperiod to -9.754 in the post-bubble subperiod.

\subsection{Robustness Analysis}

\subsubsection{Alternative Incentive Measures, Control Variables, and Estimation Methods}

The PPS measure only considers changes in the value of CEO stock and stock option holdings. The CEO's direct compensation from salary and bonus, new stock and stock option grants, long-term incentive pay, and other annual compensation might also matter. We thus define another payperformance sensitivity measure, PPS_TOT, as the dollar value change in the CEO's total firmrelated wealth per $\$ 1,000$ change in shareholder value. We repeat our analysis using PPS_TOT as the dependent variable. Using PPS_TOT as the incentive measure yields results similar to those of using PPS as the dependent variable. This result substantiates the finding of Hall and Liebman (1998), among others, that changes in the value of CEO stock-based compensation contribute to nearly all of the pay-performance sensitivity, and that CEO direct compensation has little impact on pay-performance sensitivity. ${ }^{14}$

\footnotetext{
${ }^{13}$ For either subperiod, the incentive is negatively related to firm size and total institutional share holdings, and positively related to return volatility, growth opportunities, and CEO tenure. The incentive is positively related to the concentration of institutional share holdings in all five regressions in the bubble period 1992-1999, but the coefficients on INSTCON become insignificant in four out of the five regressions and remain significant at the $5 \%$ level when $C D F(D I S P E R P)$ is used as the informativeness measure in the post-bubble period 2000-2001.

${ }^{14}$ This finding also alleviates our concerns regarding how to compute total direct compensation. For example, should we also include future direct compensation into it because firm performance might have an impact on future pay levels? Should new stock and option grants be treated as ex ante incentives or ex post bonuses? Clearly our
} 
In addition to market capitalization, net sales and total assets are other commonly used variables to measure firm size. We replace market capitalization with either net sales or total assets in our econometric models. We also include the square of firm size proxies to control for possible nonlinearities in the data. All of these alternative specifications yield similar results on the relation between $\mathrm{CEO}$ incentives and price informativeness. In unreported median regressions we also control for other factors that may be related to CEO incentives, such as the ratio of capital over sales, research and development $(\mathrm{R} \& \mathrm{D})$ expense over capital, and the investment-capital ratio (Jin, 2002). These variables are likely to capture the value of CEO effort. Including these control variables does not change our main results qualitatively. Following Core and Guay (1999), we try the log value of $\mathrm{CEO}$ tenure in the regression model to capture the possible concave relation between CEO incentives and CEO tenure. Again, our main results do not change qualitatively.

Apart from the median regressions on which we build our empirical analysis, we adopt other types of model estimation methods. We perform Fama-MacBeth type of regressions and compute standard errors based on a Fama-MacBeth procedure to correct the autocorrelation problem. We also perform OLS with robust standard errors, CEO fixed-effects OLS (Aggarwal and Samwick, 1999), and robust regressions (Hall and Liebman, 1998), respectively. ${ }^{15}$ All these regression methods generate qualitatively similar results. For brevity we do not report these results, which are available upon request.

\subsubsection{Further Analysis on Filtered Samples}

To address the concerns that some other factors drive our results, we apply our empirical analysis to several truncated samples after introducing several filtering rules. We notice that the cross-day trading independence assumption is critical for us to estimate the PIN measure. However, the existence of stealth trading (Barclay and Warner, 1993) suggests that this assumption is unlikely to be satisfied. If informed traders do indeed camouflage their private information and spread their trades over time, we expect a stock's trading volume to be highly autocorrelated. To address this

analysis is not sensitive to such choices.

${ }^{15}$ The CEO fixed-effects OLS controls for all differences in the average level of incentives across executives in the sample. Having CEO fixed effects helps alleviate the potential "unobserved endogeneity" problem if those unobservables tend to stay constant over time. A robust regression begins by screening out and eliminating gross outliers based on OLS results, and then iteratively performs weighted regressions on the remaining observations until the maximum change in weights falls below a pre-set tolerance level, say, $1 \%$. 
potential problem, we compute the autocorrelations of daily trading volumes for each stock, $A R_{i, t}$,

on an annual basis. For every fiscal year, we rank the firms into percentiles by $A R_{i, t}$ from low to high. We delete the observations whose $A R^{\prime} s$ are above the 70th, 90th, or 99th percentile levels, respectively. We then run the median regressions as specified in equation (2) on the filtered samples. This method provides a partial remedy to the violation of the cross-day trading independence assumption. We find that the estimates of the parameter of interest, $\gamma_{1}$, are in line with those based on the full sample.

We conduct another experiment in which we filter firms in financial distress out of the sample. We use the KZ index, defined in Kaplan and Zingales (1997), to measure the severity of a firm's external financing constraints. The higher the index, the more severe the financing constraint that the firm faces. We rank firms into percentiles from low to high based on the index and we delete observations whose indices are above the 70th, 90th, or 99th percentile levels, respectively. We also examine whether firms involved in mergers and acquisitions (M\&A) drive our results. We define a dummy variable $M A D$, which is equal to one if a firm engages in M\&A deals either as an acquirer or as a target in a given year, and zero otherwise. There are in total 1,671 firm-year observations with $M A D$ equal to one in the period 1992-2001, and we delete all these observations from our full sample. We run median regressions on each of the filtered samples, and again find similar results.

\section{Analysis of All Executives and Executive Teams}

We extend our above analysis to all top executives and executive teams. In Panel A of Table 6, we use PPS_EXE, the stock-based pay-performance sensitivity of the five top-paid executives of a firm, as the dependent variable, and the CDF transformations of the five price informativeness measures as our information variables. The results are qualitatively similar to those using CEO pay-performance sensitivity as the dependent variable (Table 4). Specifically, the estimated coefficients of $C D F(P I N), C D F(F E), C D F(F E P), C D F(D I S P E R)$, and $C D F(D I S P E R P)$ are respectively, $0.820,-0.698,-1.332,-1.056$, and -2.006 . All of these are significant at the $1 \%$ level and have the expected signs.

The economic significance of these estimates is large too. When the informativeness proxy is $C D F(P I N), C D F(F E), C D F(F E P), C D F(D I S P E R)$, and $C D F(D I S P E R P)$, the estimated 
pay-performance sensitivities of an executive at the 25 th percentile of stock price informativeness are respectively $\$ 0.41, \$ 0.349, \$ 0.666, \$ 0.528$, and $\$ 1.003$ smaller than those at the 75 th percentile of stock price informativeness. These figures represent separately reductions of $14.91 \%, 12.7 \%$, $24.23 \%, 19.21 \%$, and $36.49 \%$ of the median pay-performance sensitivity. (Note that the median of PPS_EXE in our sample is 2.749.)

The estimated coefficient of CEO indicator, CEOFLAG, is significantly positive in all of the five regressions, ranging from 6.042 to 8.828. In each regression, CEOFLAG is the single most significant variable among all control variables in explaining the cross-sectional differences in executive incentives. Moreover, the magnitude of its coefficient estimate is much larger than the median of $P P S \_E X E$, reaffirming that pay-performance sensitivity is much higher for CEOs than for nonCEO executives.

We sum up PPS_EXE across all five top-paid executives of a firm to obtain PPS_TEAM. It measures an executive team's incentive level. We repeat the analysis by using PPS_TEAM as the dependent variable and report the results in Panel B of Table 6. Specifically, the coefficients of $C D F(P I N), C D F(F E), C D F(F E P), C D F(D I S P E R)$, and $C D F(D I S P E R P)$ are 9.832, $-5.157,-14.471,-9.727$, and -22.431 , respectively, and all are statistically significant at the $1 \%$ level.

The median of PPS_TEAM is $\$ 24.252$ in our sample, which suggests that a median executive team's stock-based wealth would increase by $\$ 24.252$ per $\$ 1,000$ increase in shareholder value. Keeping this in mind, we find that the economic magnitude of price informativeness on the executive team's pay-performance sensitivity is quite large. The team pay-performance sensitivities, estimated at the $25 \%$ level of stock price informativeness, are $\$ 4.916, \$ 2.579, \$ 7.236, \$ 4.864$, and $\$ 11.216$ smaller than those estimated at the $75 \%$ level of price informativeness, representing respective reductions of $20.27 \%, 10.63 \%, 29.84 \%, 20.06 \%$, and $46.25 \%$ from the median of PPS_TEAM.

\section{Conclusion}

In this paper we examine the relation between executive incentives and stock price informativeness. Following Holmstrom and Tirole (1993), we develop a model that links market microstructure to managerial incentives. We empirically investigate whether stock price informativeness has a 
significant impact on pay-performance sensitivity. We use the probability of informed trading and variants of analyst earnings forecast error and forecast dispersion as proxies for price informativeness. We conduct various empirical tests and justify the key prediction that CEO pay-performance sensitivity does increase with respect to stock price informativeness. Our results are robust to alternative estimators, incentive measures, sample selections, model specifications, and estimation methods. We extend our analysis to nonCEO executives and executive teams and obtain similar findings.

Our empirical findings imply that a more informative stock price helps strengthen the payperformance relations. The results suggest that transparency in a broader sense help reconnect the executive compensation to firm performance. Besides the disclosure, the extent to which such information can be correctly interpreted by the investors and incorporated into the stock price formation process through trading matters a lot to the pay-performance relations and the effectiveness of incentive pay schemes. 


\section{Appendix: A Model Linking Market Microstructure to Executive Compensations}

We begin with a single-period model with two points of time, indexed $t=0,1$. The period is further divided into several stages. The model unfolds as follows: At the initial point of time 0, a publicly held firm is established and shares are issued on the firm's future cash flow. The terminal payoff of the firm at time 1 is: $\widetilde{r}=e+\delta$. Here $e$ is the earning determined by managerial actions, and $\delta$ is a noise term, representing factors outside the manager's control. We assume that $\delta$ is distributed normally with mean zero and variances $V_{\delta}$.

At stage 1, the firm owner (the principal) hires one manager (the agent). The owner writes a compensation contract on two performance measures, the stock price $P$ and the firm's payoff $\tilde{r}:{ }^{16}$

$$
W=a+b P+f \widetilde{r}
$$

where $a$ represents the fixed salary, $b$ and $f$ capture the sensitivities of the manager's compensation relative to $P$ and $\widetilde{r}$, respectively. Given the compensation contract, the manager chooses an effort level $e \in[0, \infty)$, which is unobservable.

At stage 2, the stock market opens. A stock market investor can observe an informative but non-contractible signal on the firm's future value at a cost. She does not search for the costly private signal on $\delta$ unless her expected value of doing so exceeds her reservation value $\mu$. The costly signal acquired by an informed investor $i$ is $\delta+\epsilon_{i}$, where $\epsilon_{i}$ is i.i.d. with mean zero and variance $V_{\epsilon}$. Informed trader $i$ submits a market order that is linear in her signal, $\beta\left(\delta+\epsilon_{i}\right)$. We assume that the total liquidity demand (of uninformed traders) in the market is $z$ and $z$ is a normally distributed variable with mean zero and variance $V_{z}$. We also assume that there are an endogenous number, $N$, of informed investors in the stock market. The total order flow observed by the market maker is $\omega=N \beta \delta+\sum_{i=1}^{N}\left(\beta \epsilon_{i}\right)+z$. The competitive market maker, given the aggregate order flow $\omega$, sets a price such that $P=E[\widetilde{r} \mid \omega] .^{17}$

At time 1, the payoff is realized, the incentive contract is honored, and the firm is liquidated. The

\footnotetext{
${ }^{16}$ We can also interpret $\widetilde{r}$ as reported accounting earnings, where we abstract from manager's earnings management incentive. Factoring the manager's incentive to misreport earnings only makes $\widetilde{r}$ noisier but does not change our results qualitatively.

${ }^{17}$ We use the firm's gross proceeds instead of the net proceeds in the pricing function so as to obtain analytically tractable solutions. Because in our model $W$ is linear in both $P$ and $\widetilde{r}$, factoring $W$ in the pricing function does not change the information content of the stock price. The stock price derived from this pricing function is informationally equivalent to the price derived from the more general pricing function specification, $P=E[(\widetilde{r}-W) \mid \omega]$. Baiman and Verrecchia (1995) and Milbourn (2003) make the same arrangement.
} 
resulting liquidation proceeds are distributed between the manager and the principal. All players but the manager in this economy are risk-neutral. The manager's preference is represented by a negative exponential utility function over her compensation $W$ with the (absolute) risk aversion coefficient $\gamma$. Her cost of choosing the effort $e$ is denoted as $C(e)=\frac{1}{2} k e^{2}$. Given her choice of effort $e$, the manager's evaluation of the normally distributed income $W$ can be represented in the certainty equivalent measure as follows:

$$
U(W, e)=E(W)-\frac{\gamma}{2} \operatorname{Var}(W)-C(e)
$$

Based on the model set-up, we solve a rational-expectation equilibrium in which the players in the real sector use the information contained in the stock price and the realized payoff to make optimal decisions, and both the real sector and the stock market attain equilibrium. We first solve the stock market equilibrium. With liquidity demand $z$, the total order flow observed by the market maker is $\omega=N \beta \delta+\sum_{i=1}^{N}\left(\beta \epsilon_{i}\right)+z$. The market maker sets a linear price schedule of the form $P=e+\lambda \omega$ (Kyle, 1985). Using standard techniques, we obtain the equilibrium value of $\lambda$ as $\lambda=V_{z}^{-\frac{1}{2}} \Gamma^{\frac{1}{2}}$, where $\Gamma=\frac{N V_{\delta}^{2}\left(V_{\delta}+V_{\epsilon}\right)}{\left[(N+1) V_{\delta}+2 V_{\epsilon}\right]^{2}}$. The expected profit of an informed trader is given by $E R=\frac{V_{\delta}\left(V_{\delta}+V_{\epsilon}\right)^{\frac{1}{2}} V_{z}^{\frac{1}{2}}}{N^{\frac{1}{2}}\left[(N+1) V_{\delta}+2 V_{\epsilon}\right]}$. A potential trader searches for the private signal if and only if the expected profit from doing so exceeds her reservation value $\mu$. Thus, the equilibrium number of informed traders $N$, is determined by

$$
\frac{V_{\delta}\left(V_{\delta}+V_{\epsilon}\right)^{\frac{1}{2}} V_{z}^{\frac{1}{2}}}{N^{\frac{1}{2}}\left[(N+1) V_{\delta}+2 V_{\epsilon}\right]}=\mu .
$$

Using the implicit function theorem, we obtain

Lemma 1 The number of informed traders $N$, (1) decreases as the investors' reservation value $\mu$ on becoming informed increases, (2) increases as the volatility of the firm's cash flow $V_{\delta}$ increases, and (3) increases as the volatility of the liquidity trading $V_{z}$ increases.

Proof. Omitted and available from the authors. Q.E.D.

Let $\rho \equiv \operatorname{Corr}(\delta, P)$, given the linear price schedule $P=e+\lambda \omega$, we have

Lemma 2 The correlation coefficient between $\delta$ and stock price $P, \rho$, and the variance of the stock 
price, $\operatorname{Var}(P)$, are given by

$$
\rho=\left[\frac{N V_{\delta}}{(N+1) V_{\delta}+2 V_{\epsilon}}\right]^{\frac{1}{2}}
$$

and

$$
\operatorname{Var}(P)=\frac{N V_{\delta}}{(N+1) V_{\delta}+2 V_{\epsilon}} V_{\delta}=\rho^{2} V_{\delta}
$$

Proof. Omitted and available from the authors. Q.E.D.

We then analyze the optimal contracting. Following Holmstrom and Tirole (1993), we transform the wage function into the following equivalent normalized form:

$$
W=\hat{a}+b P+f \hat{r}
$$

where $\hat{a}=a+f e^{*}, \hat{r}=\widetilde{r}-e^{*}$, and $e^{*}$ is the equilibrium effort level. Note that equation (A. 6) is a linear transformation of equation (A. 1) at the hypothesized equilibrium value. The contracting analysis becomes much analytically easier with the normalized wage equation, so we build our analysis on this transformed compensation function from this point onwards. One way to interpret equation (A. 6) is that besides the stock price $P$, the principal observes another signal $\hat{r}$ and include the signal into the compensation contract.

Using the standard agency-theory approach, we have:

Proposition 1 In the rational-expectations equilibrium, the optimal compensation contract can be re-written as

$$
W=\hat{a}+b\left(P-\frac{\operatorname{Cov}(P, \delta)}{\operatorname{Var}(\delta)} \hat{r}\right),
$$

with $f=-b \frac{\operatorname{Cov}(P, \delta)}{\operatorname{Var}(\delta)}$. The optimal pay-performance sensitivity $b$ is given by

$$
b=\frac{1}{1+\gamma k \operatorname{Var}(P)\left(1-\rho^{2}\right)},
$$

where $\rho \equiv \operatorname{Corr}(P, \delta)$. The optimal effort level $e^{*}$ is given by

$$
e^{*}=\frac{b}{k}
$$

Proof. Omitted and available from the authors. Q.E.D. 
In equilibrium, $f$ is negative because $\rho$ is positive. The intuition is similar to the relative performance argument put forward first in Holmstrom (1979) and then expanded in Holmstrom and Milgrom (1987). By construction, $\hat{r}$ acts as one signal, in addition to the stock price $P$, to help the principal better extract the information about the managerial effort. If $\hat{r}$ is high then the principal knows that the exogenous shock is positive, and hence lower the agent's compensation. In a different framework to analyze the use of reported accounting earnings and stock price as a basis for managerial compensation, Baiman and Verrecchia (1995) obtain a similar result: the negative weight on reported earnings in the manager's contract is used to imperfectly extract the manager's actual effort level from the stock price.

Define $x \equiv P-\frac{\operatorname{Cov}(\delta, P)}{\operatorname{Var}(\delta)} \hat{r}$. We can view $x$ as an aggregate performance index built on two performance measures, $P$ and $\hat{r}$. The compensation scheme in our model is hence based on an aggregate measure that captures various aspects of a firm's performance. ${ }^{18}$

From equation (A. 8), we have $\frac{\partial b}{\partial k}<0, \frac{\partial b}{\partial \gamma}<0$. Also note that from Lemma 2, we have $\operatorname{Var}(P)\left(1-\rho^{2}\right)=\frac{N V_{\delta}^{2}\left(V_{\delta}+2 V_{\epsilon}\right)}{\left[(N+1) V_{\delta}+2 V_{\epsilon}\right]^{2}}$. It is not hard to show that $\frac{\partial \operatorname{Var}(P)\left(1-\rho^{2}\right)}{\partial N}<0$. Combining Lemma 1 with Proposition 1, we immediately obtain:

Proposition 2 (1) The more costly it is to collect information about firm performance, the less sensitive is the pay to performance $\left(\frac{\partial b}{\partial \mu}<0\right)$.

(2) Given the number of informed traders $N$, the more volatile the cash flow, the less sensitive is the pay to performance $\left(\frac{\partial b}{\partial V_{\delta}}<0\right)$.

(3) Given the number of informed traders $N$, the more dispersed are the informed investors' opinions (or the less informative of the performance signal), the less sensitive is the pay to performance $\left(\frac{\partial b}{\partial V_{\epsilon}}<0\right)$.

Proof. Omitted and available from the authors. Q.E.D.

\footnotetext{
${ }^{18}$ Executive compensation contracts in real world are oftentimes written on a variety of performance measures such as economics value added (EVA), return on invested capital (ROIC), total returns to shareholders (TRS), and etc. The aggregate measure we propose in equation (A. 1) thus reflects the features of the incentive pay scheme in real world.
} 


\section{References}

[1] Abarbanell, J, Lanen, W, Verrecchia, R. Analysts' forecasts as proxies for investor beliefs in empirical research. Journal of Accounting and Economics 1995;20; 31-60.

[2] Aggarwal, R, Samwick, A. The other side of the trade-off: The impact of risk on executive compensation. Journal of Political Economy 1999;107; 65-105.

[3] Akinkya, B, Gift, M. Dispersion of financial analysts' earnings forecasts and the (option model) implied standard deviations of stock returns. Journal of Finance 1985;40; 1353-1365.

[4] Barron, O, Kim, O, Lim, S, Stevens D. Using analysts' foreacsts to measure properties of analysts' information environment. Accounting Review 1998;74; 421-433.

[5] Barry, C, Jennings, R. Information and diversity of analyst opinion. Journal of Financial and Quantitative Analysis 1992;27; 169-183.

[6] Baker, G, Hall, B. CEO incentives and firm size. Journal of Labor Economics 2004;22; 767-798.

[7] Barclay, M, Warner, J. Stealth trading and volatility. Journal of Financial Economics 1993;34; 281-305.

[8] Bebchuk, L, Fried, J. Executive compensation as an agency problem. Journal of Economic Perspectives 2003;17; 71-92.

[9] Bertrand, M, Mullainathan, S. Are CEOs rewarded for luck? The ones without principals do. Quarterly Journal of Economics 2001;116; 901-932.

[10] Bushman, R, Piotroski, J, Smith, A. Insider trading restrictions and analysts' incentives to follow firms. Journal of Finance 2005;60; 35-66.

[11] Chen, Q, Goldstein, I, Jiang, W. Price informativeness and investment sensitivity to stock prices. Review of Financial Studies 2006;20; 619-650.

[12] Core, J, Guay, W. The use of equity grants to manage optimal equity incentive levels. Journal of Accounting and Economics 1999;28; 151-184.

[13] Core, J, Wayne G. The other side of the trade-off: The impact of risk on executive compensation: A revised comment. University of Pennsylavania working paper 2002.

[14] Demsetz, H, Lehn, K. The structure of corporate ownership: Causes and consequences. Journal of Political Economy 1985;93; 1155-1177.

[15] Diether, K, Malloy, C, Scherbina, A. Difference of opinion and the cross section of stock returns. Journal of Finance 2002;57; 2113-2141.

[16] Durnev, A, Morck, R, Yeung, B. Value enhancing capital budgeting and firm-specific stock return variation. Journal of Finance 2004;59; 65-105.

[17] Easley, D, Hvidkjaer, S, O'Hara, M. Is information risk a determinant of asset returns? Journal of Finance 2002;57; 2185-2221.

[18] Easley, D, Kiefer, N, O’Hara, M, Paperman, J. Liquidity, information, and less-frequently traded stocks. Journal of Finance 1996;51; 1405-1436. 
[19] Easley, D, Kiefer, N, O'Hara, M, Paperman, J. The information content of the trading process. Journal of Empirical Finance 1997;4; 159-186.

[20] Easley, D, O'Hara, M. Time and the process of security price adjustment. Journal of Finance $1992 ; 47 ; 577-604$.

[21] Easley, D, O'Hara, M. Information and the cost of capital. Journal of Finance 2004;59; 15531583.

[22] Easley, D, O'Hara, M, Srinivas, P. Option volumn and stock prices: Evidence on where informed traders trade. Journal of Finance 1998;53; 431-465.

[23] Ely, K. Interindustry differences in the relation between compensation and firm performance variables. Journal of Accounting Research 1991;29; 37-58.

[24] Garen, J. Executive compensation and principal-agent theory. Journal of Political Economy $1994 ; 102 ; 1175-1199$.

[25] Gaver, J, Gaver, K. Additional evidence on the association between the investment opportunity set and coporate financing, dividend, and compensation policies. Journal of Accounting and Economics 1993;16; 125-160.

[26] Grossman, S, Stiglitz, J. On the impossibility of informationally efficient markets. American Economic Review 1980;70; 393-408.

[27] Hall, B, Liebman, J. Are CEOs really paid like bureaucrats? Quarterly Journal of Economics 1998;113; 653-691.

[28] Hartzell, J, Starks L. Insitutional investors and executive compensation. Journal of Finance 2003;58; 2351-2374.

[29] Holmstrom, B, Tirole, J. Market liquidity and performance monitoring. Journal of Political Economy 1993;101; 678-709.

[30] Holthausen, R, Verrecchia, R. The effect of informedness and consensus on price and volume behavior. Accounting Review 1990;65; 191-208.

[31] Jensen M, Murphy, K. Performance pay and top-management incentives. Journal of Political Economy 1990;98; 225-262.

[32] Jin, L. CEO compensation, diversification, and incentives. Journal of Financial Economics $2002 ; 66 ; 29-63$.

[33] Johnson, T. Forecast dispersion and the cross section of expected returns. Journal of Finance 2004;59; 1957-1978.

[34] Kaplan, S, Zingales, L. Do investment-cash flow sensitivities provide useful measures of financing constraints? Quarterly Journal of Economics 1997;112; 169-215.

[35] Kyle, A. Continuous auctions and insider trading. Econometrica 1985;57; 1315-1335.

[36] Milbourn, T. CEO reputation and stock-based compensation. Journal of Financial Economics 2003;68; 233-262. 
[37] Murphy, K 1999. Executive Compensation. In: Ashenfelter O, Card D (Eds), Handbook of labor economics, vol.3. North-Holland: Amsterdam; 1999.

[38] Piotroski, J, Roulstone, D. The influence of analysts, institutional investors, and insiders on the incorporation of market, industry, and firm-specific information into stock prices. The Accounting Review 2004;79; 1119-1151.

[39] Prendergast, C. The tenuous trade-off of risk and incentives. Journal of Political Economy $2002 ; 110 ; 1071-1102$.

[40] Schaefer, S. The dependence of pay-performance sensitivity on the size of the firm. Review of Economics and Statistics 1998;3; 436-443.

[41] Smith, C, Watts, R. The investment opportunity set and corporate financing, dividend, and financing policies. Journal of Financial Economics 1992;32; 262-292.

[42] Subrahmanyam, A, Titman, S. The going-public decision and the development of financial markets. Journal of Finance 1999;54; 1045-1082.

[43] Subrahmanyam, A. Corporate governance and financial markets. UCLA working paper 2007.

[44] Vega, C. Stock price reaction to public and private information. Journal of Financial Economics 2006;82; 103-133. 